\title{
Specific serum carotenoids are inversely associated with breast cancer risk among Chinese women: a case-control study
}

\author{
Bo Yan ${ }^{1}$, Min-Shan $\mathrm{Lu}^{1,2}$, Lian Wang ${ }^{1}$, Xiong-Fei Mo ${ }^{3}$, Wei-Ping Luo ${ }^{1}$, Yu-Feng Du ${ }^{1}$ and Cai-Xia Zhang ${ }^{1 *}$ \\ ${ }^{1}$ Department of Medical Statistics and Epidemiology, School of Public Health, Sun Yat-sen University, Guangzhou 510080, \\ People's Republic of China \\ ${ }^{2}$ Guangzhou Women and Children's Medical Center, Guangzhou Medical University, Guangzhou 510080, People's Republic \\ of China \\ ${ }^{3}$ Department of Vascular Surgery, The First Affiliated Hospital, Sun Yat-sen University, Guangzhou 510080, People's Republic \\ of China
}

(Submitted 24 May 2015 - Final revision received 25 August 2015 - Accepted 23 September 2015 - First published online 20 October 2015)

\section{Abstract}

Previous epidemiological studies have revealed the anti-cancer effect of dietary circulating carotenoids. However, the protective role of specific individual circulating carotenoids has not been elucidated. The purpose of this study was to examine whether serum carotenoids, including $\alpha$-carotene, $\beta$-carotene, $\beta$-cryptoxanthin, lycopene and lutein/zeaxanthin, could lower the risk for breast cancer among Chinese women. A total of 521 women with breast cancer and age-matched controls (5-year interval) were selected from three teaching hospitals in Guangzhou, China. Concentrations of $\alpha$-carotene, $\beta$-carotene, $\beta$-cryptoxanthin, lycopene and lutein/zeaxanthin were measured using HPLC. Unconditional logistic regression models were used to calculate OR and $95 \%$ CI using quartiles defined in the control subjects. Significant inverse associations were observed between serum $\alpha$-carotene, $\beta$-carotene, lycopene, lutein/zeaxanthin and the risk for breast cancer. The multivariate OR for the highest quartile of serum concentration compared with the lowest quartile were 0.44 (95\% CI $0.30,0.65)$ for $\alpha$-carotene, $0 \cdot 27$ (95\% CI 0.18, 0.40) for $\beta$-carotene, 0.41 (95\% CI 0.28, 0.61) for lycopene and $0 \cdot 26$ (95\% CI 0.17, $0 \cdot 38)$ for lutein/zeaxanthin. However, no significant association was found between serum $\beta$-cryptoxanthin and the risk for breast cancer. Stratified analysis by menopausal status and oestrogen receptor (ER)/progesterone receptor (PR) showed that serum $\alpha$-carotene, $\beta$-carotene, lycopene and lutein/ zeaxanthin were inversely associated with breast cancer risk among premenopausal women and among all subtypes of ER or PR status. The results suggest a protective role of $\alpha$-carotene, $\beta$-carotene, lycopene and lutein/zeaxanthin, but not $\beta$-cryptoxanthin, in breast cancer risk.

Key words: Serum carotenoids: Breast cancer: Case-control studies: Chinese women

Carotenoids are potent anticarcinogenic substances involved in antioxidant activity, stimulation of gap-junction intercellular communication and inhibition of cellular proliferation. Besides scavenging radical substances, carotenoids may stimulate the immune system and protect against breast cancer ${ }^{(1)}$.

Compared with estimates of dietary intake, serum or plasma carotenoids are better indicators of the biological availability of carotenoids. Some epidemiological studies have revealed the anti-cancer effect of circulating carotenoids. However, the protective role of individual specific serum/plasma carotenoids remains controversial. A retrospective case-control study found an inverse association ${ }^{(2)}$, whereas cohort studies ${ }^{(3-5)}$ were more likely to represent modest or null associations between serum carotenoids and breast cancer risk. In a pooled analysis of eight prospective studies of circulating carotenoids $^{(6)}$, significant negative associations with breast cancer were observed for $\alpha$-carotene, $\beta$-carotene, lutein/zeaxanthin, lycopene and total carotenoids. $\beta$-cryptoxanthin was not significantly associated with risk.

However, seven of eight studies included in this pooled analysis were conducted in western countries. Compared with western women, in whom the median age at diagnosis is 60-64 years, the age at cancer diagnosis among Chinese women was much younger. Mean age at diagnosis is 48 years $^{(7)}$, and $65 \%$ of women were premenopausal ${ }^{(8)}$. Chinese women exhibited a significantly advanced average stage on diagnosis (stage IIA $v$. stage I) on the basis of primary tumour size ${ }^{(9)}$. Moreover, although the incidence rate of female breast cancer in China was still significantly lower than that in western countries (age-standardised incidence rate of 22.1/100 000 women-years for Chinese women, 92.9/100000 women-years for American women, 69.9/100 000 women-years for European women), breast cancer had a rapid increase in China ${ }^{(10)}$. Therefore, there is an urgent need for efficient prevention strategies among Chinese women.

\footnotetext{
Abbreviations: ER, oestrogen receptor; PR, progesterone receptor.
}

* Corresponding author: Professor C.-X. Zhang, fax +86 20 87330446, email zhangcx3@mail.sysu.edu.cn 
To the best of our knowledge, only one previous study has investigated the association between specific circulating carotenoids and the risk for breast cancer in the Chinese population $^{(5)}$, and evidence for the protective effect of each individual serum carotenoid is inconsistent. People living in Guangdong, China, follow the 'traditional southern' dietary pattern $^{(11)}$ characterised by high intakes of vegetables and fruits, which is different from the dietary pattern in Shanghai.

The purpose of the present study was to examine whether serum carotenoids including $\alpha$-carotene, $\beta$-carotene, $\beta$-cryptoxanthin, lycopene and lutein/zeaxanthin may lower the risk for breast cancer among Chinese women. As the aetiologies of breast cancer may differ by receptor status, analyses were stratified by menopausal status, oestrogen receptor (ER) status, or progesterone receptor (PR) status to examine any protective effect of each carotenoid in these subgroups.

\section{Methods}

\section{Study subjects}

Details of this ongoing hospital-based case-control study, which began in 2011, have been reported previously ${ }^{(12)}$. Female subjects aged 25-70 years were consecutively recruited from three teaching and general hospitals in Guangzhou, China. All had been histologically diagnosed with breast cancer within 3 months of the recruitment interview. Subjects were natives of Guangdong province or had lived in Guangdong for at least 5 years. Women were excluded if they had a history of other cancers. From September 2011 to May 2014, a total of 521 (96.30\%) of 541 eligible cases were included in the study.

Control subjects were females with no history of any type of cancer who had been admitted to the same hospitals during the same period as the case subjects. They were frequencymatched by age (5-year interval) and were recruited from the departments of Plastic and Reconstructive Surgery, Vascular Surgery, and Ear, Nose and Throat. In total, 521 of 537 (97.02\%) controls participated. The controls were recruited from the above departments because we had no prior reason to believe that several conditions from these departments had apparent association with a dietary cause.

This study was conducted according to the guidelines laid down in the Declaration of Helsinki, and all procedures involving human subjects were approved by The Ethical Committee of School of Public Health, Sun Yat-sen University. A written informed consent form was signed by all study subjects.

\section{Data collection}

The data were collected by trained interviewers through face-to-face interviews. A structured and previously validated questionnaire was used ${ }^{(13)}$. Information on socio-demographic situation, current weight, height, menstrual and reproductive history, menopausal status, use of exogenous hormones, use of contraceptive drugs, family history of cancer, medical history, medication treatment, dietary habits, active and passive smoking, alcohol drinking and physical activities was obtained. BMI was calculated by dividing body weight $(\mathrm{kg})$ by height $(\mathrm{m})$ squared. Regular smoking was defined as smoking at least 1 cigarette/d for $>6$ consecutive months. Passive smoking was defined as exposure to others' tobacco smoke for at least $5 \mathrm{~min} / \mathrm{d}$ in the previous 5 years. Regular drinking was defined as drinking alcohol at least once per week over the past year. Postmenopausal status was defined as at least 12 months since the last menstrual cycle. Relevant medical diagnoses and pathological findings were abstracted from the medical records.

\section{Measurement of serum carotenoids}

Fasting serum samples $(5 \mathrm{ml})$ were collected in pro-coagulation tubes on the 2nd day after subjects had been admitted and kept fasting for at least $12 \mathrm{~h}$. Samples were put in a box filled with dry ice and sent to the laboratory. Sera were separated from blood cells by centrifugation ( $3000 \mathrm{rpm}$ at $4^{\circ} \mathrm{C}$ for $15 \mathrm{~min}$ ) within $1 \mathrm{~h}$ of collection. Serum samples were stored at $-80^{\circ} \mathrm{C}$ until analysis. Concentrations of $\alpha$-carotene, $\beta$-carotene, $\beta$-cryptoxanthin, lycopene and lutein/zeaxanthin were measured using HPLC. Serum carotenoids $(200 \mu \mathrm{l})$ were deproteinated with ethanol, and $\alpha$-tocopherol acetate was added as an internal standard before extraction. After extraction with hexane-butylated hydroxytoluene $(2 \mathrm{ml})$ solution, carotenoids were evaporated to dryness with $\mathrm{N}$ at room temperature. The extract was dissolved in acetonitrilemethanol-tetrahydrofuran-ammonium acetate (mobile phase B, $200 \mu \mathrm{l}, 55: 35: 5: 5, \mathrm{v} / \mathrm{v}$ ) and then a C18 HPLC column (Shiseido) and a Waters 2998 diode-array detector (Waters) were used to detect carotenoids. Mobile phase A included acetonitrilemethanol-tetrahydrofuran-ammonium acetate (85:5:5:5, v/v). A sample was injected into the column every $30 \mathrm{~min}$. Retinol and carotenoids were measured at $325 \mathrm{~nm}$ and $325 / 450 \mathrm{~nm}$, respectively. All procedures were performed by the same technician, and peaks were calculated automatically. The median betweenbatch inter-assay $\mathrm{CV}$ were $7.8 \%$ for $\alpha$-carotene, $8.6 \%$ for $\beta$-carotene, $9.7 \%$ for $\beta$-cryptoxanthin, $10.6 \%$ for lycopene and $8.0 \%$ for lutein/zeaxanthin. The with-run $\mathrm{CV}$ were $1.40 \%$ for $\alpha$-carotene, $1.50 \%$ for $\beta$-carotene, $4.00 \%$ for $\beta$-cryptoxanthin, $3.30 \%$ for lycopene and $1.70 \%$ for lutein/zeaxanthin.

\section{Statistical analysis}

Statistical analyses were performed using SPSS 19.0, and results were considered significant when $P<0.05$ (two-sided). For continuous variables, data are shown as means and standard deviations. For categorical variables, frequencies are presented as percentages. The quartiles of the measured carotenoids were defined according to the distribution of the control subjects. The socio-demographic characteristics and potential risk factors between the two groups were compared using Student's $t$ tests or Wilcoxon's rank-sum test for continuous variables and $\chi^{2}$ tests or Fisher's exact tests for categorical variables.

Unconditional logistic regression was used to estimate the OR and $95 \%$ CI of each quartile (Q1-Q4) of serum levels of specific carotenoids, setting the lowest quartile group as the reference. The association between the risk for breast cancer and the serum levels of specific carotenoids was further examined after adjusting for several potential confounders using multivariate logistic regression models. BMI (continuous variable), residence 
(urban/rural), education level (primary school or below/junior high school/senior high school/secondary technical school/ college or above), income (<2000, 2001-5000, 5001-8000, $>8000$ yuan/month), regular drinker (yes/no) and history of benign breast disease (yes/no) were regarded as potential confounders according to a comparison of baseline characteristics between cases and controls. Tests for trends were performed by entering the categorical variables (Q1-Q4) as continuous variables in the models.

As certain risk factors for breast cancer may exert different influences on premenopausal and postmenopausal women ${ }^{(14)}$, the association between specific serum carotenoids and breast cancer risk may be altered by menopausal status. Therefore, an analysis stratified by premenopausal or postmenopausal status was performed. Additionally, breast cancer defined by ER and PR status appears to be aetiologically heterogeneous ${ }^{(15)}$. Stratified analyses by ER status (ER+ or ER-) or PR status (PR+ or PR-) were carried out to assess whether breast cancer risk differs in accordance with ER or PR status. Our sample of 225 cases and 260 controls in two quartiles (Q1 and Q4) gave us $78 \%$ power to detect an OR of 0.71 for the association between serum $\beta$-cryptoxanthin and breast cancer risk at $P<0.05$ (two-tailed). We had $100 \%$ power to detect OR of $0 \cdot 44,0 \cdot 27,0.41$ and 0.26 for the association between serum $\alpha$-carotene, $\beta$-carotene, lycopene and lutein/zeaxanthin and breast cancer risk.

\section{Results}

The socio-demographic characteristics of the study subjects are presented in Table 1. Compared with control subjects, women with breast cancer were more likely to live in rural areas, have a higher BMI, be regular drinkers and have a history of benign breast disease. Case subjects were more likely to possess a lower household income and lower educational level. No significant differences were observed between the cases and controls in terms of age, number of live births, age at menarche, age at menopause, age at first live birth, menopausal status, marital status, occupation, physical activity, smoking status, history of a first-degree relative with cancer, passive smoking, oral contraceptive use or breast-feeding

The comparison of mean concentration of serum carotenoids between cases and controls is shown in Table 2. Control subjects possessed significantly higher mean concentrations of serum $\alpha$-carotene, $\beta$-carotene, $\beta$-cryptoxanthin, lycopene and lutein/zeaxanthin when compared with cases.

The OR and $95 \% \mathrm{CI}$ for breast cancer risk according to the serum concentration of specific carotenoids are presented in Table 3. After adjustment for various confounders, a significant inverse association was observed between serum $\alpha$-carotene, $\beta$-carotene, lycopene, lutein/zeaxanthin and the risk for breast cancer. The adjusted OR for the highest quartile compared with the lowest quartile were 0.44 (95\% CI 0.30, 0.65; $P_{\text {trend }}<0.01$ ) for serum $\alpha$-carotene, 0.27 (95\% CI 0.18, 0.40; $P_{\text {trend }}<0.01$ ) for $\beta$-carotene, 0.41 (95\% CI 0.28 , $\left.0.61 ; P_{\text {trend }}<0.01\right)$ for lycopene and 0.26 (95\% CI $0.17,0.38$; $\left.P_{\text {trend }}<0.01\right)$ for lutein/zeaxanthin. However, no significant association was found between serum $\beta$-cryptoxanthin and the risk for breast cancer, with an adjusted OR of 0.71 (95\% CI $0.48,1.03$ ) comparing the highest with the lowest quartile $\left(P_{\text {trend }}=0 \cdot 07\right)$.
Table 1. Socio-demographic and selected risk factors for breast cancer among breast cancer cases and controls

(Numbers and percentages; mean values and standard deviations)

\begin{tabular}{|c|c|c|c|c|c|}
\hline & \multicolumn{2}{|c|}{$\begin{array}{l}\text { Cases } \\
(n 521)\end{array}$} & \multicolumn{2}{|c|}{$\begin{array}{l}\text { Controls } \\
(n 521)\end{array}$} & \multirow[b]{2}{*}{$P$} \\
\hline & $n$ & $\%$ & $n$ & $\%$ & \\
\hline Age (years) & \multirow{2}{*}{\multicolumn{2}{|c|}{$47 \cdot 6$}} & & & 0.46 \\
\hline Mean & & & \multicolumn{2}{|c|}{$48 \cdot 0$} & \\
\hline SD & \multicolumn{2}{|c|}{$9 \cdot 4$} & \multicolumn{2}{|c|}{9.5} & \\
\hline Marital status & & & & & $0 \cdot 26$ \\
\hline Married & 492 & 94.4 & 482 & $92 \cdot 5$ & \\
\hline Unmarried/divorced/widowed & 29 & $5 \cdot 6$ & 39 & $7 \cdot 5$ & \\
\hline Residence & & & & & 0.02 \\
\hline Urban & 373 & $71 \cdot 6$ & 406 & $77 \cdot 9$ & \\
\hline Rural & 148 & 28.4 & 115 & $22 \cdot 1$ & \\
\hline Education level & & & & & $<0.01$ \\
\hline Primary school or below & 126 & $24 \cdot 2$ & 126 & $24 \cdot 2$ & \\
\hline Junior high school & 158 & $30 \cdot 3$ & 116 & $22 \cdot 3$ & \\
\hline $\begin{array}{l}\text { Senior high school/secondary technical } \\
\text { school }\end{array}$ & 128 & $24 \cdot 6$ & 133 & $25 \cdot 5$ & \\
\hline College or above & 109 & 20.9 & 146 & $28 \cdot 0$ & \\
\hline Occupation & & & & & 0.76 \\
\hline Administrator/other white collar worker & 119 & $22 \cdot 8$ & 125 & $24 \cdot 0$ & \\
\hline Blue collar worker & 140 & $26 \cdot 9$ & 146 & $28 \cdot 0$ & \\
\hline Farmer/other & 262 & $50 \cdot 3$ & 250 & $48 \cdot 0$ & \\
\hline Income (yuan/month) & & & & & $<0.01$ \\
\hline$<2000$ & 34 & $6 \cdot 5$ & 27 & $5 \cdot 2$ & \\
\hline $2001-5000$ & 162 & $31 \cdot 1$ & 128 & $24 \cdot 5$ & \\
\hline $5001-8000$ & 195 & 37.4 & 191 & $36 \cdot 7$ & \\
\hline$>8001$ & 130 & $25 \cdot 0$ & 175 & $33 \cdot 6$ & \\
\hline Physical activity (exercise for health) & & & & & 0.08 \\
\hline Never & 321 & $61 \cdot 6$ & 288 & $55 \cdot 3$ & \\
\hline Occasionally & 105 & $20 \cdot 2$ & 113 & $21 \cdot 7$ & \\
\hline Often(more than once a week) & 95 & $18 \cdot 2$ & 120 & $23 \cdot 0$ & \\
\hline BMI $\left(\mathrm{kg} / \mathrm{m}^{2}\right)$ & & & & & 0.03 \\
\hline Mean & & $3 \cdot 1$ & & $2 \cdot 6$ & \\
\hline SD & & $3 \cdot 2$ & & $3 \cdot 1$ & \\
\hline Regular smoker & 5 & 1.0 & 5 & 1.0 & 0.60 \\
\hline Passive smoking & 423 & $81 \cdot 2$ & 432 & 82.9 & 0.52 \\
\hline Regular drinker & 45 & $8 \cdot 6$ & 23 & 4.4 & $<0.01$ \\
\hline Age at menarche (years) & & & & & 0.97 \\
\hline Mean & & 4.6 & & $4 \cdot 6$ & \\
\hline SD & & 1.9 & & 1.7 & \\
\hline Menopausal status & & & & & $0 \cdot 14$ \\
\hline Premenopausal & 348 & $66 \cdot 8$ & 326 & $62 \cdot 6$ & \\
\hline Postmenopausal & 173 & $33 \cdot 2$ & 195 & $37 \cdot 4$ & \\
\hline Number of live births* & & & & & 0.10 \\
\hline Mean & & 1.9 & & 1.8 & \\
\hline $\mathrm{SD}$ & & $1 \cdot 1$ & & $1 \cdot 1$ & \\
\hline Months of breast-feedingt & & & & & 0.06 \\
\hline Mean & & $1 \cdot 7$ & & $9 \cdot 0$ & \\
\hline SD & & 4.4 & & $8 \cdot 2$ & \\
\hline Age at menopause (years) $\ddagger$ & & & & & 0.06 \\
\hline Mean & & $9 \cdot 8$ & & $9 \cdot 0$ & \\
\hline SD & & $4 \cdot 2$ & & $4 \cdot 0$ & \\
\hline Age at first live birth (years) & & & & & 0.60 \\
\hline Mean & & $5 \cdot 6$ & & 5.5 & \\
\hline SD & & 3.6 & & $3 \cdot 2$ & \\
\hline Ever used an oral contraceptive & 36 & 6.9 & 28 & 5.4 & 0.37 \\
\hline History of benign breast disease & 184 & $35 \cdot 3$ & 130 & $25 \cdot 0$ & $<0.01$ \\
\hline First-degree relative with cancer & 77 & $14 \cdot 8$ & 56 & $10 \cdot 8$ & 0.06 \\
\hline History of breast-feeding & 426 & $81 \cdot 8$ & 437 & 83.9 & 0.41 \\
\hline
\end{tabular}

* Among women who have had a live birth.

$\dagger$ Among women who had breast-fed.

‡ Among menopausal women.

Table 4 shows the association between serum carotenoid and the risk for breast cancer stratified by menopausal status. An inverse association between serum levels of $\alpha$-carotene, 
Table 2. Concentration of serum carotenoids ( $\mu \mathrm{mol} / \mathrm{l})$ among cases and controls in Guangzhou, China* (Mean values and standard deviations; median values and 25th, 75th percentiles)

\begin{tabular}{|c|c|c|c|c|c|c|c|c|c|}
\hline & \multicolumn{4}{|c|}{ Cases ( $n$ 521) } & \multicolumn{4}{|c|}{ Controls ( $n$ 521) } & \multirow[b]{2}{*}{$P$} \\
\hline & Mean & SD & Median & 25th, 75th percentile & Mean & $\mathrm{SD}$ & Median & 25th, 75th percentile & \\
\hline a-Carotene & 0.06 & 0.04 & 0.04 & $0.03,0.07$ & 0.07 & 0.06 & 0.06 & $0.04,0.08$ & $<0.01$ \\
\hline$\beta$-Carotene & 0.45 & 0.31 & 0.38 & $0.26,0.56$ & 0.57 & 0.37 & 0.48 & $0.32,0.71$ & $<0.01$ \\
\hline$\beta$-Cryptoxanthin & 0.15 & 0.13 & 0.12 & $0.08,0.18$ & 0.19 & 0.17 & 0.13 & $0.08,0.23$ & 0.01 \\
\hline Lycopene & 0.16 & 0.11 & 0.13 & $0.09,0.19$ & 0.21 & 0.14 & 0.18 & $0.11,0.26$ & $<0.01$ \\
\hline Lutein/zeaxanthin & 0.57 & 0.31 & 0.52 & $0.39,0.69$ & 0.70 & 0.34 & 0.65 & $0.46,0.86$ & $<0.01$ \\
\hline
\end{tabular}

* Wilcoxon's rank-sum test comparing the median consumption levels between cases and controls.

Table 3. Risk of breast cancer according to quartiles of serum carotenoids (Odds ratios and $95 \%$ confidence intervals)

\begin{tabular}{|c|c|c|c|c|c|c|c|c|}
\hline & \multirow{2}{*}{$\frac{\mathrm{Q1}}{\mathrm{OR}}$} & \multicolumn{2}{|c|}{ Q2 } & \multicolumn{2}{|c|}{ Q3 } & \multicolumn{2}{|c|}{ Q4 } & \multirow[b]{2}{*}{$P_{\text {trend }}$} \\
\hline & & OR & $95 \% \mathrm{Cl}$ & OR & $95 \% \mathrm{Cl}$ & OR & $95 \% \mathrm{Cl}$ & \\
\hline \multicolumn{9}{|l|}{$a$-Carotene } \\
\hline No. of cases/controls & $194 / 130$ & \multicolumn{2}{|c|}{$145 / 131$} & \multicolumn{2}{|c|}{$101 / 130$} & \multicolumn{2}{|c|}{$81 / 130$} & \\
\hline Crude & 1 & 0.74 & $0.54,1.03$ & 0.52 & $0.37,0.73$ & 0.42 & $0.29,0.60$ & $<0.01$ \\
\hline Adjusted* & 1 & 0.75 & $0.54,1.06$ & 0.59 & $0.41,0.85$ & 0.44 & $0.30,0.65$ & $<0.01$ \\
\hline \multicolumn{9}{|l|}{$\beta$-Carotene } \\
\hline No. of cases/controls & $200 / 130$ & \multicolumn{2}{|c|}{$143 / 130$} & \multicolumn{2}{|c|}{$111 / 131$} & \multicolumn{2}{|c|}{$67 / 130$} & \\
\hline Crude & 1 & 0.72 & $0.52,0.99$ & 0.55 & $0.39,0.77$ & 0.34 & $0.23,0.48$ & $<0.01$ \\
\hline Adjusted* & 1 & 0.63 & $0.45,0.89$ & 0.50 & $0.35,0.72$ & 0.27 & $0.18,0.40$ & $<0.01$ \\
\hline \multicolumn{9}{|l|}{$\beta$-Cryptoxanthin } \\
\hline No. of cases/controls & $133 / 130$ & \multicolumn{2}{|c|}{$162 / 130$} & \multicolumn{2}{|c|}{$134 / 131$} & \multicolumn{2}{|c|}{$92 / 130$} & \\
\hline Crude & 1 & 1.22 & $0.87,1.70$ & 1.00 & $0.71,1.41$ & 0.69 & $0.48,0.99$ & 0.05 \\
\hline Adjusted $^{*}$ & 1 & $1 \cdot 26$ & $0 \cdot 89,1 \cdot 78$ & 1.02 & $0.71,1.46$ & 0.71 & $0.48,1.03$ & 0.07 \\
\hline \multicolumn{9}{|l|}{ Lycopene } \\
\hline No. of cases/controls & $188 / 130$ & \multicolumn{2}{|c|}{$177 / 131$} & \multicolumn{2}{|c|}{$87 / 130$} & \multicolumn{2}{|c|}{$69 / 130$} & \\
\hline Crude & 1 & 0.93 & $0.68,1.28$ & 0.46 & $0.33,0.66$ & 0.37 & $0.25,0.53$ & $<0.01$ \\
\hline Adjusted $^{\star}$ & 1 & 1.01 & $0.72,1.41$ & 0.48 & $0.33,0.70$ & 0.41 & $0.28,0.61$ & $<0.01$ \\
\hline \multicolumn{9}{|l|}{ Lutein/zeaxanthin } \\
\hline No. of cases/controls & $218 / 130$ & \multicolumn{2}{|c|}{$147 / 131$} & \multicolumn{2}{|c|}{$98 / 130$} & \multicolumn{2}{|c|}{$58 / 130$} & \\
\hline Crude & 1 & 0.67 & $0.49,0.92$ & 0.45 & $0.32,0.63$ & 0.27 & $0.18,0.39$ & $<0.10$ \\
\hline Adjusted* & 1 & 0.69 & $0.50,0.97$ & 0.43 & $0.30,0.62$ & 0.26 & $0.17,0.38$ & $<0.10$ \\
\hline
\end{tabular}

* OR adjusted for BMI, residence, education levels, income, regular drinker and a history of benign breast disease.

$\beta$-carotene, lutein/zeaxanthin and the risk for breast cancer was found in both premenopausal and postmenopausal women. Serum $\beta$-cryptoxanthin was not significantly associated with the risk for breast cancer in pre- and postmenopausal women. The inverse association between serum lycopene and breast cancer risk was only observed among premenopausal women, with an adjusted OR of 0.36 (95\% CI 0.22 , $0 \cdot 60)$ comparing the highest quartile with the lowest quartile $\left(P_{\text {trend }}<0 \cdot 01\right)$.

Stratified analyses by ER and PR status showed that $\alpha$-carotene, $\beta$-carotene, lycopene and lutein/zeaxanthin were inversely associated with breast cancer risk among all subtypes of ER or PR status. $\beta$-cryptoxanthin was not associated with breast cancer risk either in ER or in PR subjects (Table 5).

\section{Discussion}

This study investigated the relationship between serum carotenoid concentration and breast cancer risk. High levels of serum $\alpha$-carotene, $\beta$-carotene, lycopene and lutein/zeaxanthin were found to be associated with lower risk for breast cancer. Serum $\alpha$-carotene, $\beta$-carotene and lutein/zeaxanthin were found to be inversely associated with breast cancer risk in pre- and postmenopausal women. A stratified analysis by ER and PR status showed that serum $\alpha$-carotene, $\beta$-carotene, lycopene and lutein/zeaxanthin were inversely associated with breast cancer risk among all subtypes of ER or PR status. Serum $\beta$-cryptoxanthin was not associated with breast cancer risk.

Previous findings regarding the protective effect of circulating carotenoids on breast cancer risk have been mixed. The protective effect of serum $\alpha$-carotene, $\beta$-carotene, lycopene and lutein/zeaxanthin observed in the present study is consistent with a pooled analysis of eight prospective studies published in $2012^{(6)}$. This analysis, which included 3055 cases and 3956 matched controls, reported inverse associations between circulating $\alpha$-carotene (highest $v$. lowest quintile, relative risk (RR) $0.87 ; 95 \%$ CI $0.71,1.05 ; P_{\text {trend }}=0.04$ ) $\beta$-carotene (highest $v$. lowest quintile, RR 0.83; $95 \%$ CI $0.70,0.98 ; P_{\text {trend }}=0.02$ ), lycopene (highest $v$. lowest quintile, RR 0.78; $95 \%$ CI 0.62, 0.99; 
Serum carotenoids and breast cancer risk

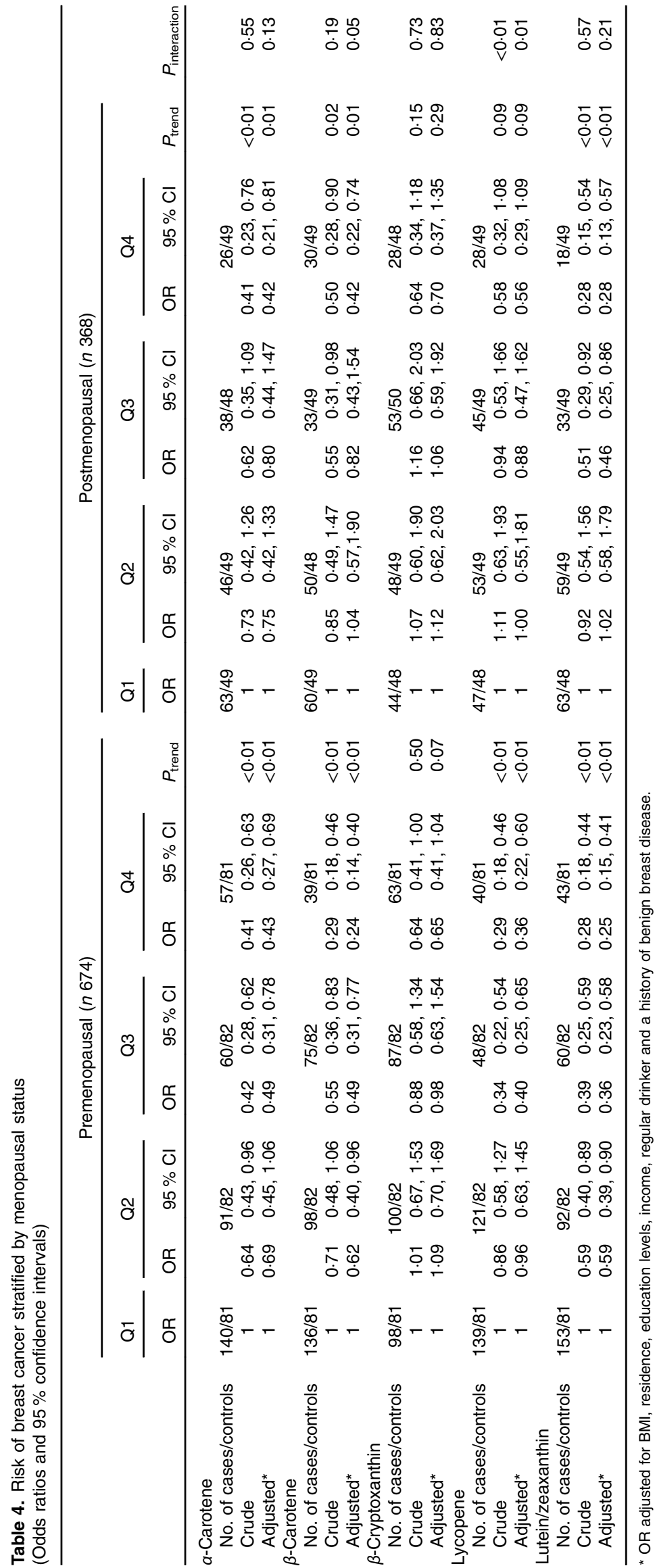


B. Yan et al.

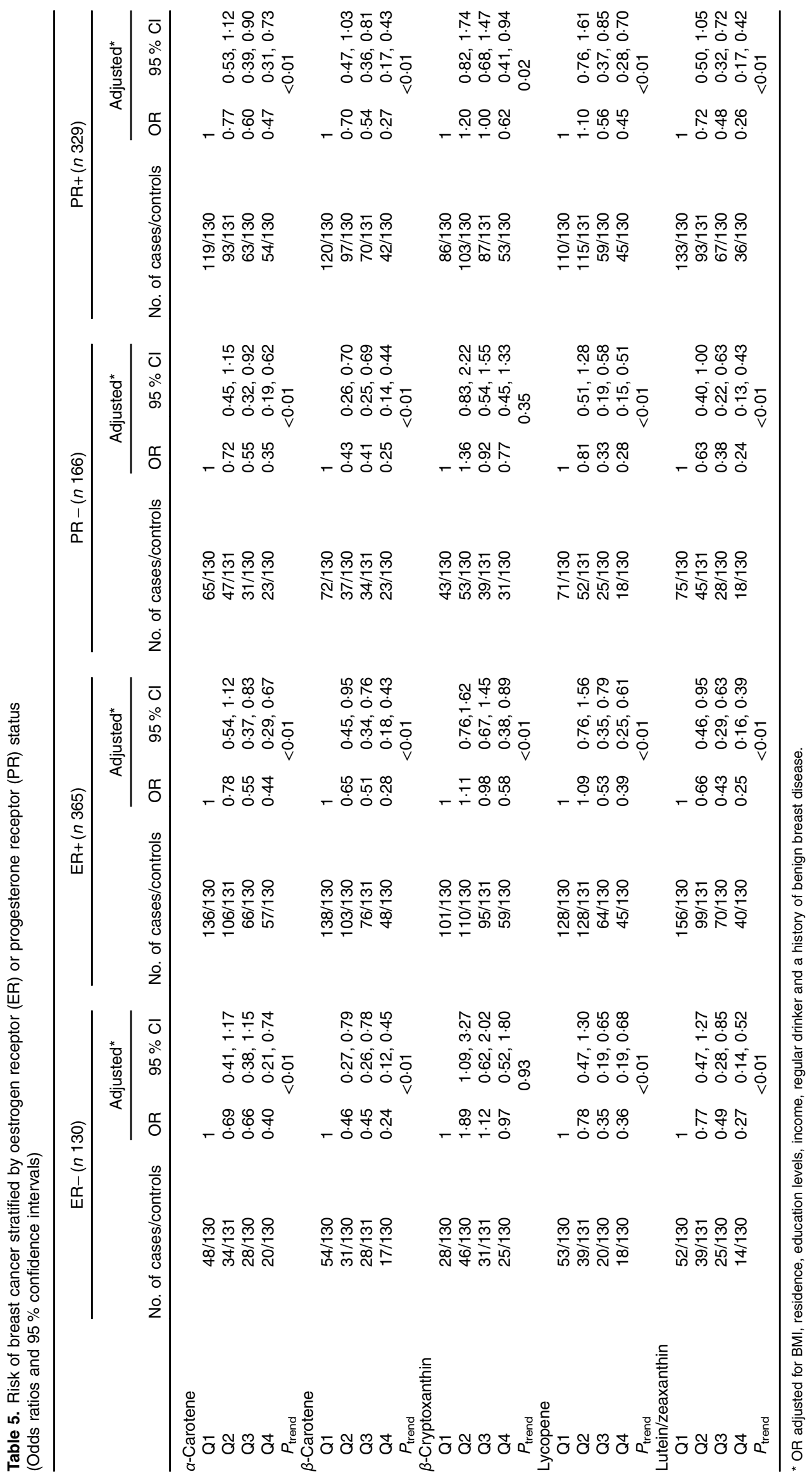


$P_{\text {trend }}=0.02$ ), lutein/zeaxanthin (highest $v$. lowest quintile, RR $0.84 ; 95 \%$ CI $\left.0.70,1.01 ; P_{\text {trend }}=0.05\right)$ and breast cancer risk. However, circulating $\beta$-cryptoxanthin was not related to breast cancer risk. Other prospective studies also showed that serum/ plasma $\alpha$-carotene ${ }^{(3,16,17)}, \beta$-carotene ${ }^{(3,16,18)}$ lycopene $^{(18,19)}$ and lutein/zeaxanthin ${ }^{(3,16,19)}$ was associated with decreased risk for breast cancer. Most previous studies ${ }^{(2-4,6,16-19)}$ have pointed to a protective role for at least one individual serum/plasma carotenoid. However, three ${ }^{(5,20,21)}$ of those recently published studies $^{(5,20-22)}$, including a study in Shanghai, China ${ }^{(5)}$, indicated that none of the individual circulating carotenoids (including $\alpha$-carotene, $\beta$-carotene, $\beta$-cryptoxanthin, lycopene and lutein/zeaxanthin) reduce breast cancer risk. One hospitalbased case-control study even reported the deleterious effect of plasma $\beta$-carotene on Korean women ${ }^{(23)}$.

Those studies that failed to find evidence for a protective role of specific serum or plasma carotenoids may have been limited by a relatively small number of cases (201 cases) ${ }^{(22)}$ or restricted to a certain group of subjects, such as highly educated volunteers $^{(20)}$ or middle-aged or older female subjects ${ }^{(5,21)}$, rather than the general population. Contrary to our findings, the previous study in Shanghai, China ${ }^{(5)}$, observed no association between specific plasma carotenoids and the risk for breast cancer. The distinct differences in dietary habits between Shanghai and Guangdong females may be responsible for the inconsistent reports. Vegetables, particularly dark green leafy vegetables, are good sources of carotenoids. Compared with Shanghai women ${ }^{(24)}$, Guangdong women ${ }^{(25)}$ were more likely to eat vegetables (total vegetables: Shanghai women $v$. Guangdong women, 304 (SD 174) v. 458 (SD 252) g/d), especially dark green leafy vegetables, which are rich in $\alpha$-carotene, $\beta$-carotene and lutein/zeaxanthin (dark green vegetables: Shanghai women $v$. Guangdong women, 92 (SD 65) $v$. $244(\mathrm{SD} 163) \mathrm{g} / \mathrm{d})$. This may account for the finding that specific carotenoids were observed to protect against breast cancer among women in Guangdong, but not among those in Shanghai. It has been reported that the association between $\beta$-carotene and cancer risk is likely to be influenced by the source of $\beta$-carotene (food or supplement) and the doses involved $^{(26)}$. In our study, most subjects attained $\beta$-carotene from dietary sources rather than supplements. This may partially explain the discrepant results.

Our study showed that serum $\beta$-cryptoxanthin was not statistically related to the risk for breast cancer. Previous reports on the association between circulating $\beta$-cryptoxanthin and breast cancer risk have been inconsistent. Several studies $^{(5,6,16,18,23)}$ reported no inverse associations for circulating $\beta$-cryptoxanthin and breast cancer risk after adjustment for other carotenoids or risk factors. In contrast, one recent nested case-control study conducted in French women showed a protective effect of plasma $\beta$-cryptoxanthin on breast cancer risk $^{(4)}$. Mean serum $\beta$-cryptoxanthin was 0.15 (SD $0 \cdot 13$ ) in our study, which was markedly lower than that in the Education Nationale-European Prospective Investigation into Cancer and Nutrition study (mean 0.23 (SD 0.16) $)^{(4)}$. Relatively low serum $\beta$-cryptoxanthin concentration among the general population in China might help to explain the discrepancies. It is also known that carotenoids provide particular protection against breast cancer among smokers, because of the aggravated oxidative stress among this group ${ }^{(27)}$. In the present study, the smoking rate of subjects was extremely low (1\%). The null association between $\beta$-cryptoxanthin and breast cancer risk may be related to the limited number of Chinese women smokers.

Consistent with our study, some previous studies have shown that serum $\alpha$-carotene, $\beta$-carotene ${ }^{(28)}$, lycopene ${ }^{(29)}$ and lutein ${ }^{(22)}$ were inversely associated with breast cancer risk in both preand postmenopausal women. However, the protective role of serum lycopene was only observed among premenopausal women in our study. The Shanghai Women's Health Study ${ }^{(5)}$ also reported the parallel effect of plasma lycopene on breast cancer risk only among premenopausal women, with an OR (95\% CI) of $0.36(0 \cdot 16,0 \cdot 80)$ comparing the highest with the lowest quartile $\left(P_{\text {trend }}=0 \cdot 06\right)$. Dissimilar characteristics (such as oestrogen exposure and oxidative stress status) between preand postmenopausal women may account for this finding ${ }^{(30)}$. Lycopene inhibits cancer cell proliferation under the influence of oestrogen exposure ${ }^{(31)}$ and was found to be protective in premenopausal subjects, who have higher levels of oestrogen. Premenopausal women were also shown to be more susceptible to the protection afforded by antioxidants (including lycopene) because of aggravated oxidative stress, in comparison with postmenopausal women ${ }^{(32)}$

The relatively few epidemiological studies that have examined associations between individual serum carotenoids and the risk for breast cancer stratified by ER or PR status have reported differing results. The significant protective effect of serum $\alpha$-carotene, $\beta$-carotene, lycopene and lutein/zeaxanthin for all subtypes of ER and PR status in the present study was consistent with some previous findings. Tamimi et al. ${ }^{(16)}$ found a negative association with plasma $\alpha$-carotene for ER- (highest $v$. lowest quintile, OR 0.50; $95 \%$ CI 0.28, 0.91; $\left.P_{\text {trend }}=0.05\right)$ and ER+ (highest $v$. lowest quintile, OR $0.72 ; 95 \%$ CI $0.50,1.04 ; P_{\text {trend }}=$ 0.03 ) breast cancer. A prospective study ${ }^{(18)}$ conducted in the USA suggested that $\beta$-carotene, lycopene and lutein were protective in both ER- and ER+ breast cancer patients. In contrast, a pooled analysis ${ }^{(6)}$ reported that $\alpha$-carotene and $\beta$-carotene reduced breast cancer risk in ER- patients but not in ER+ patients. No association between plasma lycopene and breast cancer risk was observed among ER+ and PR + women in the Shanghai Women's Health Study ${ }^{(21)}$. Although the anti-cancer role of carotenoids was supported by an experimental study indicating that carotenoids inhibited proliferation of different hormone-defined breast cancer cell lines ${ }^{(33)}$, the protective effect of serum $\beta$-cryptoxanthin on breast cancer risk was found neither in ER- nor in PR- women. The relatively small sample size might have caused a chance result or insufficient statistical power in the analysis stratified by ER or PR status. Studies with a larger sample size are warranted to clarify this association.

A protective role for carotenoids in breast cancer aetiology is biologically plausible. Carotenoids may protect against DNA damage by neutralising oxygen species ${ }^{(34)}$ and activating the antioxidant response element transcription system ${ }^{(35)}$. Besides their antioxidant potential, some carotenoids such as $\alpha$-carotene, $\beta$-carotene and $\beta$-cryptoxanthin are metabolised to retinol, which is involved in cell differentiation ${ }^{(36,37)}$. Carotenoids also contribute to intercellular communication ${ }^{(38)}$, 
cell proliferation ${ }^{(39)}$ and cell apoptosis regulation ${ }^{(40,41)}$. In addition, carotenoids influence carcinogenesis through genetic mechanisms ${ }^{(42-44)}$.

Our study had several strengths. To the best of our knowledge, only one previous study has examined the association between circulating carotenoids and breast cancer among Chinese women ${ }^{(5)}$. This study contributes evidence for the protective role of each carotenoid in women with different menopausal and ER/PR statuses. Furthermore, serum carotenoids were chosen as the biomarkers, to reflect carotenoid levels without being influenced by food patterns, racial differences and other environmental factors ${ }^{(45)}$. More objective results can be delivered by measuring serum carotenoids instead of estimating dietary intake.

Nevertheless, the current study had some limitations that should be taken into account when interpreting the results. First, the study design did not allow causal associations to be confirmed. Serum samples were collected after the diagnosis of breast cancer, and breast cancer itself might influence circulating carotenoids levels. However, a prospective study ${ }^{(46)}$ found no variation in single serum carotenoid levels between breast cancer survivors and control subjects. Second, selection and information biases could have distorted the results. To minimise selection bias, we were careful to exclude all control subjects with any diagnoses related to breast cancer or habitual dietary changes. The similar catchment areas and length of hospitalisation of all subjects, and the relatively high response rate, also reduced selection bias. To minimise information bias, serum carotenoid measurements were performed by the same trained technician. In addition, the lower inter-assay and intra-assay CV showed that the measurement of each carotenoid was relatively accurate and precise. Third, a single-sample measurement may be defective. However, a previous study found that serum carotenoid measurements were reasonably consistent over time because carotenoids are lipid soluble and relatively stable ${ }^{(47)}$. Therefore, a single sample is adequately representative of an individual's long-term exposure ${ }^{(48)}$. Finally, potential confounding variables may not have been adequately excluded. It is possible that lifestyles were different among cases and controls. However, a wide range of known predictors was considered, including active smoking, regular drinking and family history.

In conclusion, this study supports the hypothesis of a protective role of $\alpha$-carotene, $\beta$-carotene, lycopene and lutein/zeaxanthin but not $\beta$-cryptoxanthin on breast cancer risk. Circulating $\alpha$-carotene, $\beta$-carotene, lycopene and lutein/zeaxanthin were observed to be inversely associated with breast cancer risk among all subtypes of ER or PR status.

\section{Acknowledgements}

The authors gratefully acknowledge the cooperation of the study participants.

This study was jointly supported by the New Teachers' Fund for Doctor Stations, Ministry of Education of China (no. 20100171120057), the National Natural Science Foundation of China (no. 81102188) and the Open-Lab Fund of Sun Yat-sen University in 2011 (no. KF201140). The funders had no role in the design, analysis or writing of this article.
The authors' responsibilities were as follows: B. Y. conducted the data collection, analysed the data and wrote this paper. M.-S. L. conducted the laboratory measurement. X.-F. M. was responsible for connecting and coordinating the field work. L. W., W.-P. L. and Y.-F. D. participated in the data collection. C.-X. Z. constructed the project design, supervised and contributed to the manuscript writing.

The authors have no conflicts of interest.

\section{References}

1. Garattini E, Bolis M, Garattini SK, et al. (2014) Retinoids and breast cancer: from basic studies to the clinic and back again. Cancer Treat Rev 40, 739-749.

2. Ito Y, Ryuichiro KCG, Sasaki R, et al. (1999) A study on serum carotenoid levels in breast cancer patients of Indian women in Chennai (Madras), India. J Epidemiol 5, 306-314.

3. Tamimi RM, Colditz GA \& Hankinson SE (2009) Circulating carotenoids, mammographic density, and subsequent risk of breast cancer. Cancer Res 69, 9323-9329.

4. Pouchieu C, Galan P, Ducros V, et al. (2014) Plasma carotenoids and retinol and overall and breast cancer risk: a nested case-control study. Nutr Cancer 66, 980-988.

5. Dorjgochoo T, Gao Y, Chow W, et al. (2009) Plasma carotenoids, tocopherols, retinol and breast cancer risk: results from the Shanghai Women Health Study (SWHS). Breast Cancer Res Tr 117, 381-389.

6. Eliassen AH, Hendrickson SJ, Brinton LA, et al. (2012) Circulating carotenoids and risk of breast cancer: pooled analysis of eight prospective studies. J Natl Cancer Inst 104, 1905-1916.

7. Bhoo-Pathy N, Yip CH, Hartman M, et al. (2013) Breast cancer research in Asia: adopt or adapt Western knowledge? Eur J Cancer 49, 703-709.

8. Cui X, Dai Q, Tseng M, et al. (2007) Dietary patterns and breast cancer risk in the Shanghai breast cancer study. Cancer Epidemiol Biomarkers Prev 16, 1443-1448.

9. Sivasubramaniam PG, Zhang BL, Zhang Q, et al. (2015) Breast cancer disparities: a multicenter comparison of tumor diagnosis, characteristics, and surgical treatment in China and the U.S. Oncologist 20, 1044-1050.

10. Sung H, Rosenberg PS, Chen WQ, et al. (2015) Female breast cancer incidence among Asian and Western populations: more similar than expected. I Natl Cancer Inst 107, djv107.

11. He Y, Ma G, Zhai F, et al. (2009) Dietary patterns and glucose tolerance abnormalities in Chinese Adults. Diabetes Care 32, 1972-1976.

12. Zhang C, Pan M, Li B, et al. (2013) Choline and betaine intake is inversely associated with breast cancer risk: a two-stage case-control study in China. Cancer Sci 104, 250-258.

13. Zhang CX \& Ho SC (2009) Validity and reproducibility of a food frequency Questionnaire among Chinese women in Guangdong province. Asia Pac J Clin Nutr 18, 240-250.

14. Colditz GA \& Rosner B (2000) Cumulative risk of breast cancer to age 70 years according to risk factor status: data from the Nurses' Health Study. Am J Epidemiol 10, 950-964.

15. Althuis MD, Fergenbaum JH, Garcia-Closas M, et al. (2004) Etiology of hormone receptor-defined breast cancer: a systematic review of the literature. Cancer Epidemiol Biomarkers Prev 10, 1558-1568.

16. Tamimi RM, Hankinson SE, Campos H, et al. (2005) Plasma carotenoids, retinol, and tocopherols and risk of breast cancer. Am J Epidemiol 161, 153-160. 
17. Toniolo P, Van Kappel AL, Akhmedkhanov A, et al. (2001) Serum carotenoids and breast cancer. Am J Epidemiol 12, $1142-1147$

18. Sato R, Helzlsouer KJ, Alberg AJ, et al. (2002) Prospective study of carotenoids, tocopherols, and retinoid concentrations and the risk of breast cancer. Cancer Epidemiol Biomarkers Pre 11, 451-457.

19. Dorgan JF, Sowell A, Swanson CA, et al. (1998) Relationships of serum carotenoids, retinol, alpha-tocopherol, and selenium with breast cancer risk: results from a prospective study in Columbia, Missouri (United States). Cancer Causes Control 9 , 89-97.

20. Maillard V, Kuriki K, Lefebvre B, et al. (2010) Serum carotenoid, tocopherol and retinol concentrations and breast cancer risk in the E3N-EPIC study. Int J Cancer 127, $1188-1196$

21. Sesso HD, Buring JE, Zhang SM, et al. (2005) Dietary and plasma lycopene and the risk of breast cancer. Cancer Epidemiol Biomarkers Prev 14, 1074-1081.

22. Hulten K, Van Kappel AL, Winkvist A, et al. (2001) Carotenoids, alpha-tocopherols, and retinol in plasma and breast cancer risk in northern Sweden. Cancer Causes Control 12, 529-537.

23. Kim M, Ahn SH, Son BH, et al. (2010) Plasma antioxidant concentration, not superoxide dismutase polymorphism, is associated with breast cancer risk in Korean women. Nutr Res 30, 705-713.

24. Bao P, Shu X, Zheng Y, et al. (2012) Fruit, vegetable, and animal food intake and breast cancer risk by hormone receptor status. Nutr Cancer 64, 806-819.

25. Zhang C, Ho SC, Chen Y, et al. (2009) Greater vegetable and fruit intake is associated with a lower risk of breast cancer among Chinese women. Int J Cancer 125, 181-188.

26. Larsson SC, Bergkvist L \& Wolk A (2010) Dietary carotenoids and risk of hormone receptor-defined breast cancer in a prospective cohort of Swedish women. Eur J Cancer 46, 1079-1085.

27. Yokusa B, Mete N, NMU D, et al. (2014) Effects of active and passive smoking on antioxidant enzymes and antioxidant micronutrients. Biotechnol Biotechnol Equip 19, $117-123$

28. Kabat GC, Kim M, Adams-Campbell LL, et al. (2009) Longitudinal study of serum carotenoid, retinol, and tocopherol concentrations in relation to breast cancer risk among postmenopausal women. Am J Clin Nutr 90, 162-169.

29. Epplein M, Shvetsov YB, Wilkens LR, et al. (2009) Plasma carotenoids, retinol, and tocopherols and postmenopausal breast cancer risk in the Multiethnic Cohort Study: a nested case-control study. Breast Cancer Res 11, R49.

30. Spicer DV \& Pike MC (2000) Future possibilities in the prevention of breast cancer: luteinizing hormone-releasing hormone agonists. Breast Cancer Res 2, 264-267.

31. Hirsch K, Atzmon A, Danilenko M, et al. (2007) Lycopene and other carotenoids inhibit estrogenic activity of $17 \beta$-estradiol and genistein in cancer cells. Breast Cancer Res Treat 104, 221-230.
32. Victorino VJ, Panis C, Campos FC, et al. (2013) Decreased oxidant profile and increased antioxidant capacity in naturally postmenopausal women. Age (Dordr) 35, 1411-1421.

33. Babich H, Krupka ME, Nissim HA, et al. (2005) Differential in vitro cytotoxicity of (-)-epicatechin gallate (ECG) to cancer and normal cells from the human oral cavity. Toxicol In Vitro 19, 231-242

34. Elliott R (2005) Mechanisms of genomic and non-genomic actions of carotenoids. Biochim Biophys Acta 1740, 147-154.

35. Ben-Dor A, Steiner M, Gheber L, et al. (2005) Carotenoids activate the antioxidant response element transcription system. Mol Cancer Ther 4, 177-186.

36. di Masi A, Leboffe L, De Marinis E, et al. (2015) Retinoic acid receptors: from molecular mechanisms to cancer therapy. Mol Aspects Med 41, 1-115.

37. Tang X \& Gudas LJ (2011) Retinoids, retinoic acid receptors, and cancer. Annu Rev Patbol 6, 345-364.

38. Chalabi N, Delort L, Satih S, et al. (2007) Immunohistochemical expression of RAR $\alpha$, RAR $\beta$, and $\mathrm{Cx} 43$ in breast tumor cell lines after treatment with lycopene and correlation with RT-QPCR. J Histochem Cytochem 55, 877-883.

39. Chryssanthi DG, Grehoris FNL, Iatrou G, et al. (2007) Inhibition of breast cancer cell proliferation by style constituents of different crocus species. Anticancer Res 27, 357-362.

40. Hua S, Kittler R \& White KP (2009) Genomic antagonism between retinoic acid and estrogen signaling in breast cancer. Cell 137, 1259-1271.

41. Cui Y, Lu Z, Bai L, et al. (2007) $\beta$-Carotene induces apoptosis and up-regulates peroxisome proliferator-activated receptor $\gamma$ expression and reactive oxygen species production in MCF-7 cancer cells. Eur J Cancer 43, 2590-2601.

42. Jenab M, Slimani N, Bictash M, et al. (2009) Biomarkers in nutritional epidemiology: applications, needs and new horizons. Hum Genet 125, 507-525.

43. Wang S, Wang F, Shi X, et al. (2009) Association between manganese superoxide dismutase (MnSOD) Val-9Ala polymorphism and cancer risk - a meta-analysis. Eur J Cancer $\mathbf{4 5}$, 2874-2881.

44. King-Batoon A, Leszczynska JM \& Klein CB (2008) Modulation of gene methylation by genistein or lycopene in breast cancer cells. Environ Mol Mutagen 49, 36-45.

45. Al-Delaimy W, Ferrari P, Slimani N, et al. (2005) Plasma carotenoids as biomarkers of intake of fruits and vegetables: individual-level correlations in the European Prospective Investigation into Cancer and Nutrition (EPIC). Eur J Clin Nutr 59, 1387-1396.

46. Al-Delaimy WK, Natarajan L, Sun X, et al. (2008) Reliability of plasma carotenoid biomarkers and its relation to study power. Epidemiology 19, 338-344.

47. Comstock GW, Burke AE, Hoffman SC, et al. (2001) The repeatability of serum carotenoid, retinoid, and tocopherol concentrations in specimens of blood collected 15 years apart. Cancer Epidemiol Biomarkers Prev 10, 65-68.

48. McEligot AJ, Shirley CLR, Flatt SW, et al. (1999) Plasma carotenoids are biomarkers of long-term high vegetable intake in women with breast cancer. J Nutr 129, 2258-2263. 